\title{
Applying Online Image Analysis to Simultaneously Evaluate the Removals of Suspended Solids and Color from Textile Wastewater in Chemical Flocculated Sedimentation
}

\author{
R. F. Yu ${ }^{1, *}$, H. W. Chen ${ }^{2}$, W. P. Cheng ${ }^{1}$, and H. D. Huang ${ }^{1}$ \\ ${ }^{1}$ Department of Safety, Health and Environmental Engineering, National United University, Miao-Li 360, Taiwan, R. O. C. \\ ${ }^{2}$ Department of Environmental Science and Engineering, Tunghai University, Taichung 407, Taiwan, R. O. C.
}

Received 17 June 2013; revised 15 August 2014; accepted 5 November 2014; published online 6 February 2017

\begin{abstract}
The removal of suspended solids (SS) and color is critically important for textile wastewater treatment processes. Typically, chemical coagulation and sedimentation have been used as pretreatment processes to remove SS and color from textile wastewater. The effective removal of SS depends significantly on the particle size distribution, density, and fractal dimension. In practice, a batch settling test is used in the laboratory to evaluate the performance of chemical coagulation for the removal of SS. In this paper, we present the application of digital image analysis (DIA) for on-line and simultaneous measurement of the variations of the characteristics of particles in textile wastewater. This technology was used during a batch settling test to measure the characteristics of particles, including the mean gray value $(\mathrm{MGV})$ of the captured images, particle size (i.e., equivalent diameter (ED)), total area, total volume, the fractal dimension, and the mean red/green/blue $(\mathrm{R} / \mathrm{G} / \mathrm{B})$ values of the captured images. The on-line DIA data were used as input to regression and artificial neural network (ANN) models that predicted the efficiencies of SS removal and color removal in real textile wastewater after chemical coagulation and sedimentation. The experimental results indicated that the ANN models predicted both the SS and color removal efficiencies precisely, with correlation coefficients $\left(\mathrm{R}^{2}\right)$ of 0.93 to 0.96 . Thus, digital image analysis and ANN models can be used to simultaneously evaluate the removal of SS and color from textile wastewater by chemical coagulation.
\end{abstract}

Keywords: artificial neural networks, chemical coagulation, sedimentation, color removal, fractal dimension, image analysis, particle size, suspended solids

\section{Introduction}

Chemical coagulation/flocculation and sedimentation are among the most commonly used and cost-effective processes for removing suspended solids (SS), organic contaminants, color, and toxic materials for textile wastewater (Papic et al., 2004; Kumar et al., 2008; Merzouk et al., 2011; Verma et al., 2012). In Taiwan, chemical coagulation/flocculation is the most important pretreatment process to remove SS and color from textile wastewaters (Kao et al., 2001). The removals of $\mathrm{SS}$ and color by chemical coagulation/flocculation depend on the particle size distribution and the morphology of the flocculated particles (Aguilar et al., 2003; Sophonsiri and Morgenroth, 2004; Yu et al., 2006; Ofir et al., 2007; Zheng et al., 2011; Wu et al., 2012). Typically, a batch jar test is used to determine the optimal $\mathrm{pH}$ and dosage required for the effective removal of SS and color from textile wastewater (Metcalf and Eddy, 2002). Laser particle-size analyzers and the photometric dispersion analyzer (PDA) were developed to measure particle size and to monitor coagulation (Gregory, 1985; Huang

* Corresponding author. Tel.: +886 37 382279; fax: +886 37382765 .

E-mail address: rfyu@nuu.edu.tw (R. F. Yu).

ISSN: 1726-2135 print/1684-8799 online

(C) 2017 ISEIS All rights reserved. doi:10.3808/jei.201500303 and Liu, 1996; Williams et al., 2007). In addition, the optical meter and turbidmeter also have been used to measure the sizes of particles in water treatment processes (Ebie et al., 2006; Cheng et al., 2008). However, these methods typically are used to measure only one of the particles' characteristics. In addition, the reliability of the signals and the on-line application of such methods are still in question, and most of these methods are still expensive and difficult to maintain (Jarvis et al., 2005; Gregory, 2009).

Digital image analysis (DIA) is an economical method, and it easily can be used for on-line monitoring of many industrial processes (Prats-Montalban et al., 2011). Various DIA methods have been used for the monitoring and control of processes in water and wastewater treatment applications. DIA has been used for the on-line monitoring of the true color of textile wastewater (Yu et al., 2005) and to characterize the size distribution of the floc in wastewaters (Govoreanu et al., 2004; He et al., 2012). The DIA method also has been used to identify the structure and characteristics of flocs and to evaluate their settling efficiency (Grijspeerdt and Verstraete, 1997; Chakraborti et al., 2000, 2003; Wang et al., 2009; Verma et al., 2010; Zheng et al., 2011). DIA methods also have been used to identify the protozoa and metazoa in typical activated sludge as well as the filamentous and non-filamentous bacteria in water and wastewater effluents after treatment (Contreras et al., 2004; Ginoris et al., 2007). In our previous study, an on- 
line DIA system was set up to measure particle size distribution and the morphology of particles in wastewater simultaneously (Yu et al., 2009a).

Artificial neural network (ANN) models, especially the back-propagation neural network (BPN) model, are very effective in representing the relationships between input and output variables in non-linear and complex systems. ANN models have been used to address the prediction and control problems of many water and wastewater processes, including biological nutrient removal, Fenton oxidation, chlorination, UV disinfection, and sludge treatment (Yu et al., 2005, 2009b, 2013; Elemen et al., 2012; Kim et al., 2012; Kumar and Venkateswarlu, 2012). The removal of SS and color by chemical coagulation depends on several complex physical and chemical phenomena that are affected by multiple parameters, such as coagulant dosage, particle size distribution, density, and fractal dimension. Therefore, the process may be difficult to evaluate by traditional mathematical models, so an ANN model was used in this study because it was very effective in representing the relationships between input and output variables in complex, non-linear systems (Choi and Park, 2001; Senthilkumar, 2007).

In this study, the DIA was used for the on-line and simultaneous measurement of the variations of particles and to $\log$ the $\mathrm{MGV} / \mathrm{R} / \mathrm{G} / \mathrm{B}$ data of the captured images during the batch settling of chemical coagulation. Then, these on-line DIA data were used in regression and artificial neural network (ANN) models to predict the SS and color removal efficiencies for real textile wastewater after chemical coagulation and sedimentation. This combination of DIA monitoring and the ANN model has the potential to provide an automatic, rapid, and more effective evaluation of both SS and color removals of chemical coagulation than the traditional jar test and the particle measurements by laser particle-size analyzers or the PDA.

\section{Materials and Methods}

\subsection{Reactor and DIA System}

Figure 1 shows the details of the setting reactor and the DIA system used in this study. A batch-type, laboratory-scale settling tank with an effective volume of $3.6 \mathrm{~L}(60 \mathrm{~cm}$ high, $10 \mathrm{~cm}$ long, $6 \mathrm{~cm}$ wide) was used. The width of $6.0 \mathrm{~cm}$ was designed to ensure that the DIA system easily could identify the image of each particle in the wastewater samples during settling. The DIA device had a high-magnification micro-lens with a high-resolution charge coupled device (CCD) (480 TV lines; Marlin F-080C) that was used to capture images of the particles in the sample. A halogen illuminator (LSH-150F) with an intensity of $25 \mathrm{~W} / 120 \mathrm{~V}$ was used as the light source. The detected images were analyzed following the image analysis processes, including image pretreatment (remove luminance), image enhancement (lookup table/convolution/filter), image segmentation (entropy, binarization), feature extraction, and image representation. Using this high-resolution $\mathrm{CCD}$, one pixel on the detected image would occupy an area of approximately $2.25 \mu^{2}$; therefore, particles with EDs greater

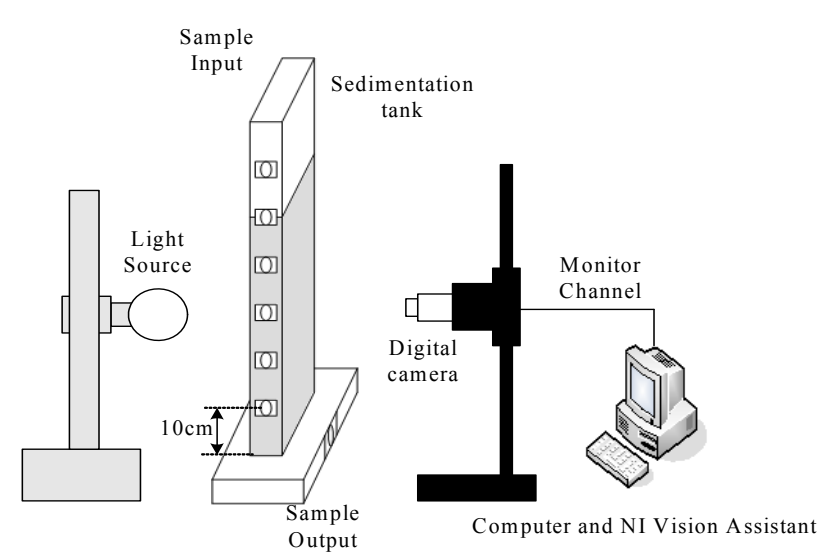

Figure 1. Schematic diagram of the settling tank and the digital image analysis (DIA) device.

than $10 \mu \mathrm{m}$ could be identified easily. The images that were detected on-line were analyzed using the software programmed by the NI Vision Assistant (National Instruments, USA) for the simultaneous identification of particles and the measurement of their characteristics. After these processes, various parameters associated with the captured images of the particles were acquired, including the MGV (Mean Gray Value) and RGB (Red, Green and Blue) values, particle size (ED), total area, total volume, and the fractal dimension of the particles using the methods proposed by Yu et al. (2005, 2009 a). The ED of each particle in the captured images was calculated based on the "Projected Area Diameter" method, which means the diameter of a theoretical circle that contains the same projected area as the irregular particle.

\subsection{Batch Settling Experiments}

Typically, textile wastewaters contain large amounts of $\mathrm{SS}$ and color, and chemical coagulation is one of the effective processes used to remove SS and color. Therefore, samples of real textile wastewater were used in this study. The samples were acquired from the influent of a full-scale, textile wastewater treatment plant in Miao-Li City, Taiwan. The samples contained $144 \sim 290 \mathrm{mg} / \mathrm{L}$ of SS, 854 1,837 ADMI $31 \mathrm{WL}$ units of color, and $241 \sim 453 \mathrm{mg} / \mathrm{L}$ of chemical oxygen demand (COD). True color based on AMDI units of samples was measured due to the color discharge limit in Taiwan. The raw wastewater that was collected was placed in a 20 L storage tank for $30 \mathrm{~min}$ to remove the settleable particles; the supernatant was moved into a coagulation system. Poly aluminum chloride (PAC) coagulant (Panreac, Spain), with doses ranging from 80 to $210 \mathrm{mg} / \mathrm{L}$, was added into the coagulation system to conduct a typical chemical coagulation process (rapid mixing at $100 \mathrm{RPM}$ for $5 \mathrm{~min}$ and slow mixing at 30 RPM for $20 \mathrm{~min}$ ). Subsequently, the wastewater sample was removed and placed in a batch settling tank (Figure 1) for solid-liquid separation. The CCD was set at $10 \mathrm{~cm}$ below the surface of the liquid to capture the images of the particles as they passed through. The images were captured every $10 \mathrm{~s}$ by the CCD, so about 180 images were obtained in the batch 


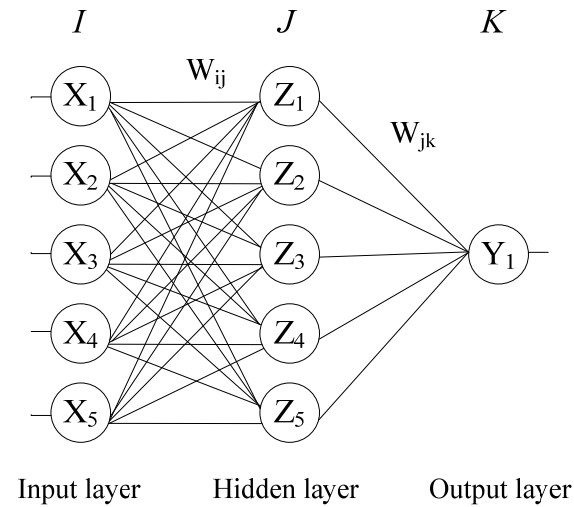

Figure 2. Architecture of the BPN model used in this study.
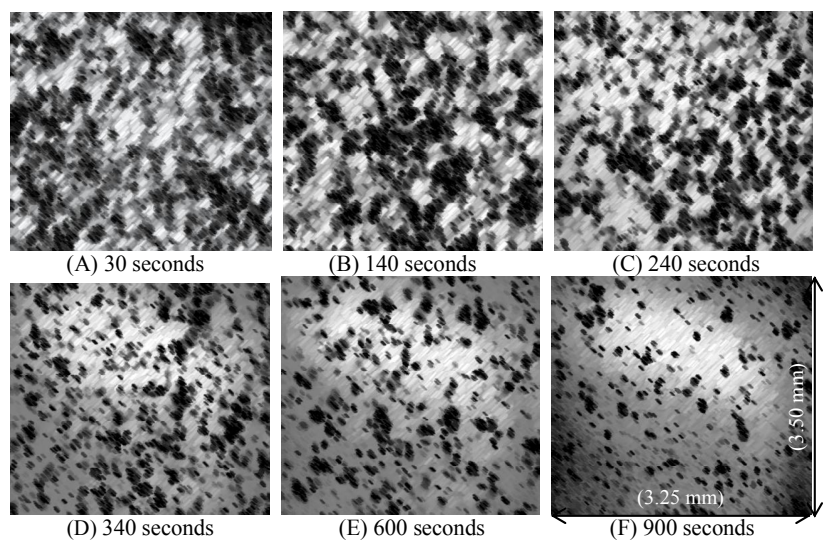

Figure 3. Series of captured images for different settling time.

settling test. Particles in the images were identified by the NI Vision Assistant, and the various parameters for captured images and the identified particles were measured simultaneously. Sixty runs of the chemical coagulation/flocculation and settling experiments were conducted in this study. For each run, the concentration of SS and the true color of the sample before coagulation/flocculation and after settling were measured using methods 2540D (SS) and 2120E (ADMI true color) in Standard Methods (APHA et al., 2005).

\subsection{ANN and Regression Models}

A typical back-propagation neural network (BPN) model consists of three layers, i.e., input, hidden, and output layers. The model was developed using Super PCNeuron 5.0 software (Yeh, 2009), and it was used to build the ANN prediction models in this study. Figure 2 shows the architecture of the BPN model that was used. The correlations of input vector $\left(X_{i}\right)$, hidden vector $\left(Z_{j}\right)$, and output vector $\left(Y_{k}\right)$ are defined as shown in the following equations.

Hidden layer: $Z_{j}=f\left(\sum_{i=1}^{I} w_{i_{j}} \times X_{i}\right)$

Output layer: $Y_{k}=f\left(\sum_{j=1}^{J} w_{j k} \times Z_{j}\right)$
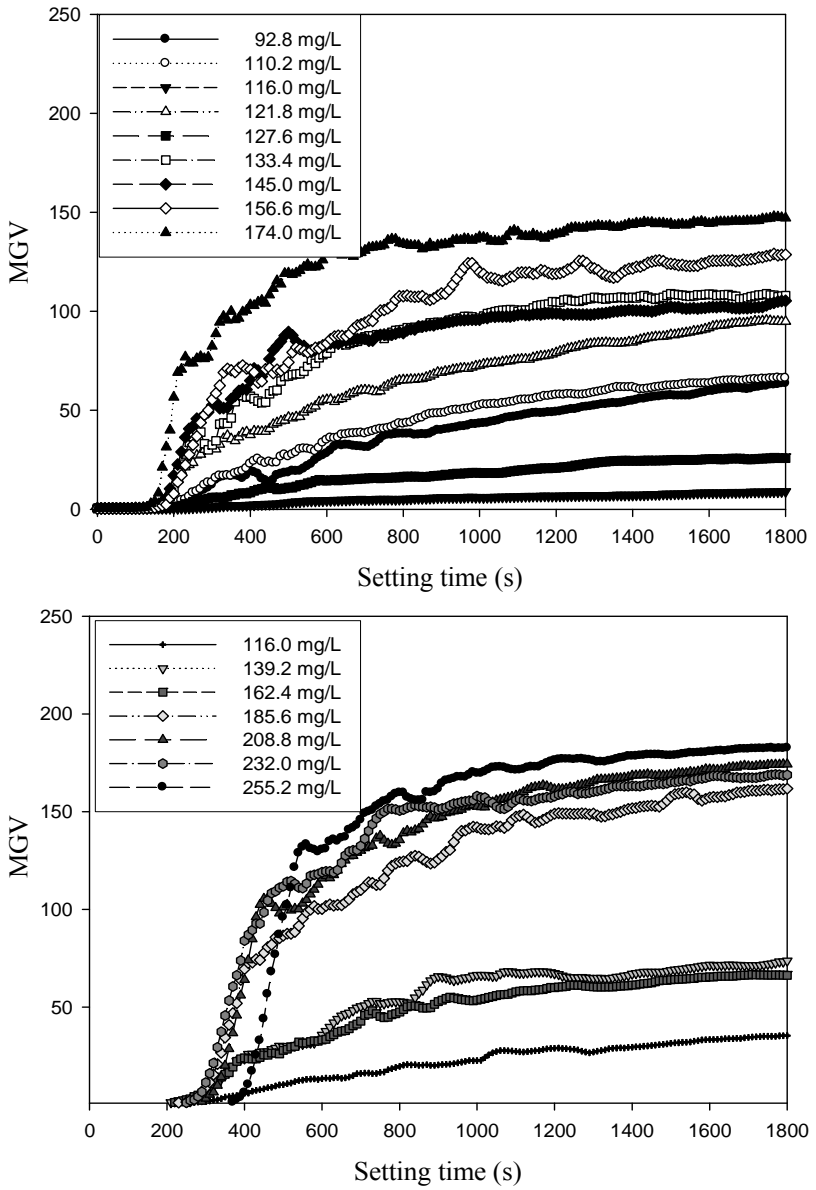

Figure 4.Variations of mean gray value (MGV) of captured images for different PAC doses during the particles settling.

where $X_{i,}, Z_{k}$, and $Y_{j}$ are the input, hidden, and output vectors, respectively; $W_{i j}$ and $W_{j k}$ are connecting weights from $X_{i}$ to $Z_{j}$ and $Z_{j}$ to $Y_{k}$, respectively. The sigmoid function was used as the activation function. This BPN model used the generalized delta-learning rule as its training algorithm, the gradient descent method to minimize error, and Root Mean Square (RMS) to evaluate the performance of the training and test procedures. Also, a traditional linear regression was used based on Microsoft Excel 2010 software.

\section{Results and Discussion}

\subsection{Variations of MGV of the Captured Images in Settling}

Figure 3 shows a series of typical images that were captured at different settling times. In the initial settling period, large, aggregated particles occupied the entire image. Thus, separate particles could not be identified, and particle sizes and morphologies could not be measured. After $240 \mathrm{~s}$ of settling, fewer and smaller particles were found in the captured image because most of the larger particles had settled. The particles were identified easily after about 900 s of settling, because only a few small particles were observed in the image. 


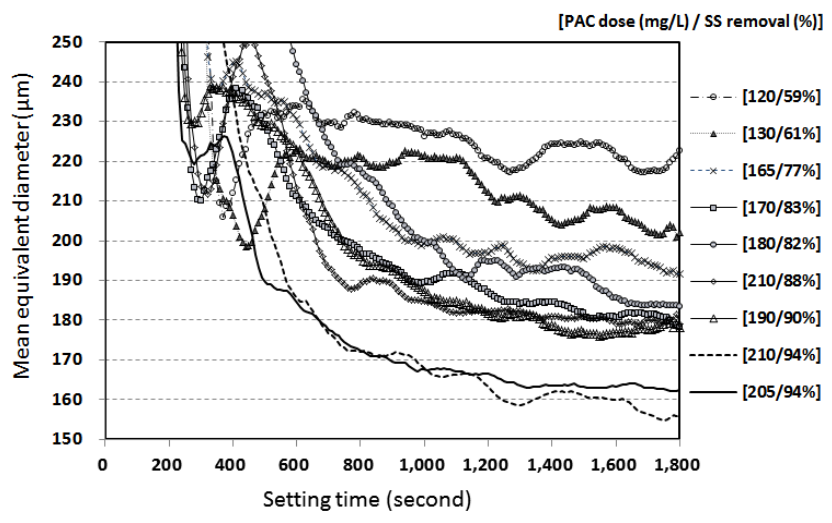

Figure 5. Variations of particle size (ED) during the settling for different PAC doses.

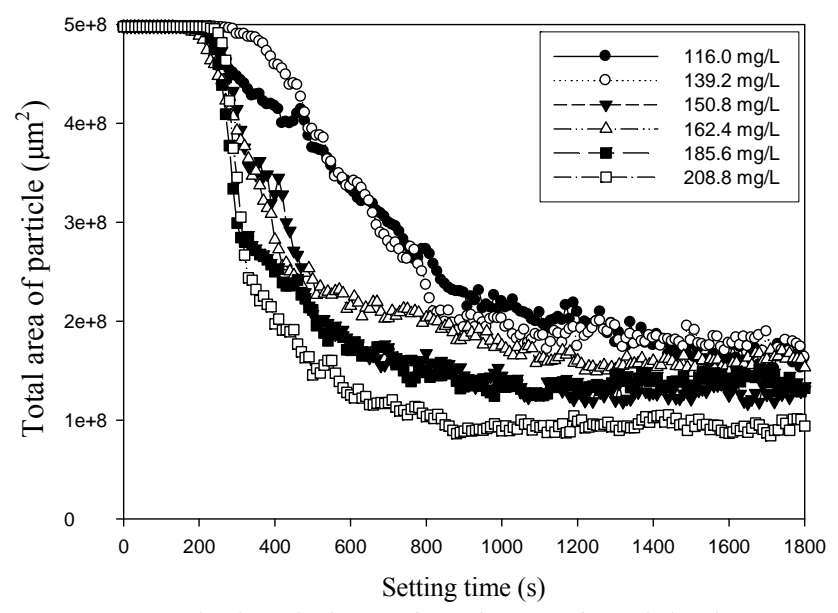

Figure 6. Typical variations of total area of particles in detected images during the settling period for different PAC doses.

The gray value of a pixel of an image uses binary representation with the resolution of $8 \mathrm{bpp}$ (bits per pixel), meaning that 0 is black and that the maximum value of 255 is white. According to the resolution of CCD, a total of 786,432 $(1024 \times 768)$ pixels were located in each captured image in this study. NI Vision Assistant software was used to measure the gray value of each pixel, and the mean gray value (MGV) of the captured image represents the average gray value of the 786,432 pixels in the image. The pixels in the images that included SS always had low gray values. Thus, the images captured from the samples of textile wastewater that contained high SS or color typically tended to have reduced MGVs, so MGV could be a potential indicator of the level of SS or color in textile wastewater.

Figure 4 shows the typical variations of the MGVs of the images obtained while the particles were settling for different doses of PAC. Very low MGVs, near zero, were found at the beginning of the settling process because the coagulated particles were dominant and occupied the images that were obtained during this period. The MGVs increased significantly after $200 \sim 300$ seconds of settling, and they became stable after $1,000 \sim 1,200$ seconds of continuous settling. By this time, most of the particles had settled, and part of the color also had been removed. The MGVs increased to around 150 units when the doses of PAC were greater than $170 \sim 180$ $\mathrm{mg} / \mathrm{L}$; however, further increases in the doses of PAC did not result in significant increases in the MGVs of the images. Theoretically, the small and suspended particles will be aggregated by the added PAC to form larger particles. The aggregated and larger particles occupy less area on the detected image, resulting in an increase of MGV. Therefore, increases of the MGV of the images caused by the higher PAC doses were observed. Therefore, a large MGV of an image tends to indicate the effective removal of SS from the sample by chemical coagulation. However, further increases of PAC doses did not significantly increase the MGVs because overdosing with PAC did not contribute to the aggregation of the particles. Similar results also were presented by Chakraborti et al. (2000) using a different indicator of elongation ratio.

\subsection{Variations of Particle Size during the Settling of Par- ticles}

In chemical coagulation, the addition of chemical coagulants and proper mixing enlarge the sizes of the particles, which, in turn, increases the efficiency of the settling of the particles. Thus, variations of particle size in chemical coagulation are critical for attaining the desired SS removal efficiencies, which were monitored on-line by the DIA system in this study. Figure 5 shows typical variations of the particle sizes in the images that were obtained during the settling process. When the particles were just beginning to settle, many aggregated particles occupied the entire detection range, and the separated particles were difficult to identify. After about $500 \mathrm{~s}$ of settling, the particles in the images could be identified easily, and the ED of every particle could be calculated.

The EDs of the particles in the images decreased from around $200 \sim 240$ to $160 \sim 200 \mu \mathrm{m}$ as the settling time increased because particles with large EDs settled more easily and more rapidly than particles with small EDs. Variations of the EDs of the particles became very low after a settling time of about $1,000 \sim 1,200 \mathrm{~s}$, indicating that the required settling time for these cases was around 20 min for the observed particle sizes. The EDs of the suspended particles were about 150 $\sim 200 \mu \mathrm{m}$, and suspended particles with small EDs typically were found in the experiments in which high doses of PAC were administered, resulting in higher SS removal efficiencies (Figure 5).

\subsection{Variations of Total Area and Total Volume of the Settled Particles}

Solids flux is defined as the total mass of solids or sludge passing through a given unit area of the clarifier. A solids flux curve, which can be derived from the results of the batch sludge settling test, usually is used to design the secondary clarifier of an activated sludge system. However, the solids flux curve must be developed in the laboratory, and many experiments involving a large number of SS measurements are 
required. In this study, the on-line monitoring of particles using the DIA system can calculate the total area and the total volume of the particles that pass a defined area, and this information is representative of the "solids flux." The total area and total volume of particles also can indicate the total mass or number of particles passing through a given area in this study. For two wastewater samples in which the particles had similar EDs but different total areas, the sample that had the larger total area of particles may present better SS removal efficiency.

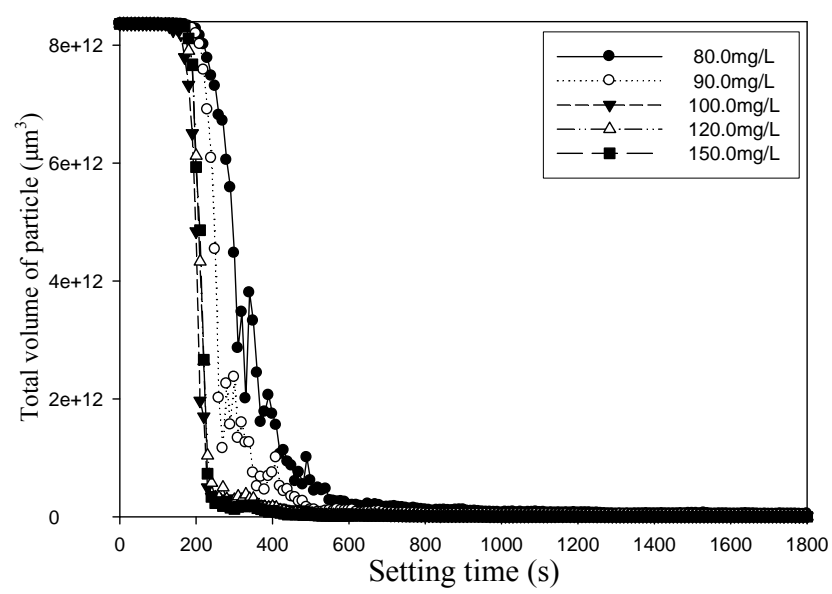

Figure 7. Typical variations of total volume of particles in detected images during the settling period for different PAC doses.

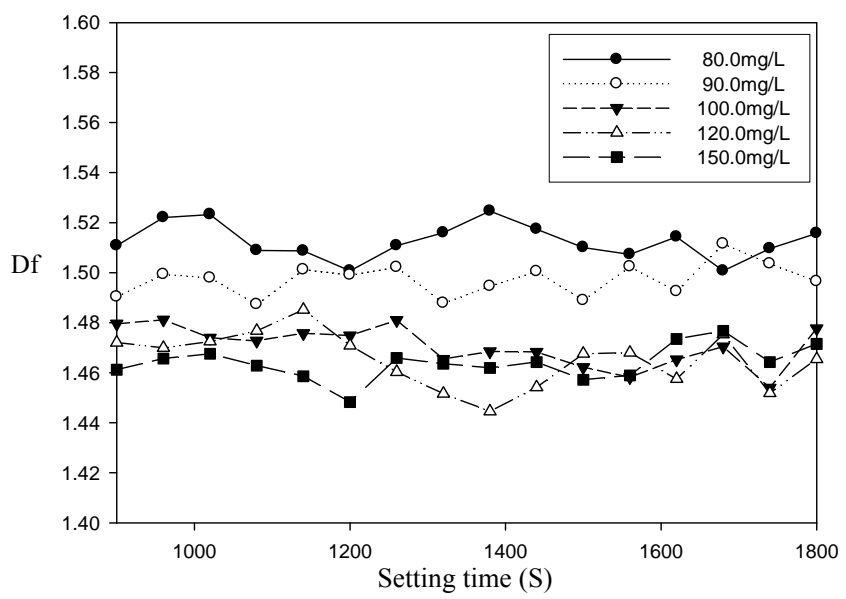

Figure 8. Typical variations of mean Df of particles in detected images during the settling for different PAC doses.

Figures 6 and 7 show the variations of the total area and the total volume of particles in the images that were obtained during the settling period for different doses of PAC. The total area of the particles is the summation of the areas of all of the particles identified in the image that was obtained, and this area can be calculated using NI Vision software. The volume of each particle was calculated based on the assumption that all the particles were spherical, thus, the volume of each parti-
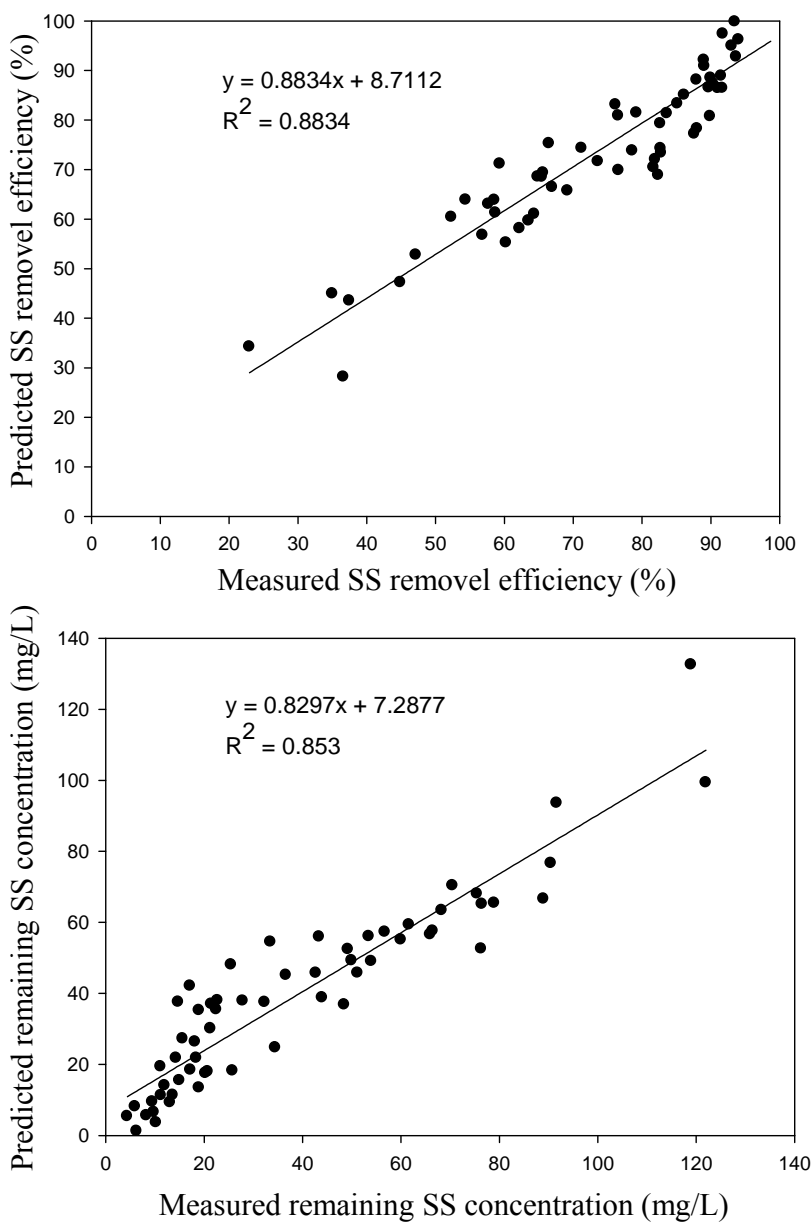

Figure 9. Prediction results of regression models for measured and predicted SS removal efficiencies and remaining SS concentrations.

cle also can be calculated based on its ED, and the total volume is the summation of the volumes of all of the particles identified in the image that was obtained.

In the initial settling period, the measured total area and total volume can only be used as reference data, because the separated particles cannot be identified clearly. However, relatively large total area and large total volume of particles in the initial settling period are reasonable. The total area of particles decreased from the initial $5.0 \times 10^{8}$ to $0.3 \sim 2.0 \times 10^{8} \mu \mathrm{m}^{2}$ after about $1,000 \sim 1,200 \mathrm{~s}$ of settling. Typically, higher doses of PAC resulted in lower total areas of particles (Figure 6).

The measured total volume of particles decreased from around $8.0 \times 10^{12}$ to $2.0 \times 10^{9} \sim 1.8 \times 10^{11} \mu \mathrm{m}^{3}$ after around $800 \sim 900 \mathrm{~s}$ of settling. Typically, higher doses of PAC caused lower final total areas of particles (Figure 7), indicating that more particles were aggregated due to the higher dosages of PAC. This decrease in the total areas of the particles also resulted in the increase of $\mathrm{MGV}$ of the detected image, as presented in Figure 4. It also was noted that the decreased profiles for measured total area and total volume were similar to a typical solids flux curve (Metcalf and Eddy, 2002). More significant decreases of total area and total volume of parti- 
cles were typically found to be caused by higher doses of PAC, which resulted in higher SS removal efficiencies. Therefore, the slopes of the decreasing curves of total area and total volume of particles from the initial point to the stable values were used as indicators to evaluate the SS removals. According to the experimental data from the DIA analysis in this study, the stable values were defined when the changes of total area and total volume were less than of $1.0 \%$ in $10 \mathrm{~s}$.

Table 1. Details of the Identifications of Input Parameters of the SS and Color Removals in Regression and BPN Prediction Models

\begin{tabular}{|c|c|c|c|}
\hline $\begin{array}{l}\text { Input } \\
\text { parameter }\end{array}$ & Parameter identification & \multicolumn{2}{|c|}{$\begin{array}{l}\text { Correlation } \\
\left(\mathrm{R}^{2}\right)\end{array}$} \\
\hline \multicolumn{4}{|c|}{ For SS removal efficiency and remaining SS predictions } \\
\hline MGV & $\begin{array}{l}\text { Average MGV of each image after setting } \\
\text { time of } 1,200 \text { seconds }\end{array}$ & 0.76 & \\
\hline S-MGV & $\begin{array}{l}\text { Slope of the MGV curve from setting } \\
\text { time } 0 \text { to a stable value }\end{array}$ & 0.68 & \\
\hline ED & $\begin{array}{l}\text { Average ED of particles in each image } \\
\text { after setting time of } 1,200 \text { seconds }\end{array}$ & 0.62 & \\
\hline $\mathrm{D}_{\mathrm{f}}$ & $\begin{array}{l}\text { Average } D_{f} \text { of particles in each image } \\
\text { after setting time of } 1,200 \text { seconds }\end{array}$ & 0.65 & \\
\hline TV & $\begin{array}{l}\text { Average total volume of particles in each } \\
\text { image after setting time of } 1,200 \text { seconds }\end{array}$ & 0.71 & \\
\hline S-TV & $\begin{array}{l}\text { Slope of the total volume curve from } \\
\text { setting time } 0 \text { to a stable value }\end{array}$ & 0.55 & \\
\hline TA & $\begin{array}{l}\text { Average total area of particles in each } \\
\text { image after setting time of } 1,200 \text { seconds }\end{array}$ & 0.59 & \\
\hline S-TA & $\begin{array}{l}\text { Slope of the total area curve from setting } \\
\text { time } 0 \text { to a stable value }\end{array}$ & 0.51 & \\
\hline \multicolumn{4}{|c|}{ For Color removal efficiency and remaining color predictions } \\
\hline MGV & $\begin{array}{l}\text { Average MGV of each images after } \\
\text { setting time of } 1,200 \text { seconds }\end{array}$ & 0.72 & \\
\hline S-MGV & $\begin{array}{l}\text { Slope of the MGV curve from setting } \\
\text { time } 0 \text { to a stable value }\end{array}$ & 0.61 & \\
\hline $\mathrm{R}_{\mathrm{i}}, \mathrm{G}_{\mathrm{i}}, \mathrm{B}_{\mathrm{i}}$ & $\begin{array}{l}\text { The average } R, G, B \text { values of each image } \\
\text { at the initial setting time of } 150 \text { seconds }\end{array}$ & $\begin{array}{l}0.36 \\
0.23\end{array}$ & 0.16 \\
\hline $\mathrm{R}_{\mathrm{s}}, \mathrm{G}_{\mathrm{s}}, \mathrm{B}_{\mathrm{s}}$ & $\begin{array}{l}\text { The average } R, G, B \text { values of each image } \\
\text { after setting time of } 1,200 \text { seconds }\end{array}$ & $\begin{array}{l}0.66 \\
0.70\end{array}$ & 0.74, \\
\hline
\end{tabular}

\subsection{Variations of Mean Fractal Dimension in Particle Se- ttling}

Fractal dimension $\left(\mathrm{D}_{\mathrm{f}}\right)$ is an important factor of particle morphology, and it has been regarded as a key factor that affects SS removal efficiency in wastewater treatment (Chakraborti et al., 2000; Zhong et al., 2011). Typically, a large, compact particle has a lower $\mathrm{D}_{\mathrm{f}}$ than a small, non-compact particle, resulting in a higher settling velocity, making it easy to remove by sedimentation (Chakraborti et al., 2003; Bushell et al., 2005). The DIA method that we used easily can measure the area and perimeter of each particle in the images that are obtained, thus, the mean fractal dimension of particles in the image can be calculated simultaneously based on the areaperimeter method (Chakraborti et al., 2003; Yu et al., 2009a).

Figure 8 shows typical variations of the mean $D_{f}$ of an image during settling. At the beginning of settling, the mean $\mathrm{D}_{\mathrm{f}}$ cannot be calculated because the particles cannot be iden- tified. The $\mathrm{D}_{\mathrm{f}}$ was around $1.40 \sim 1.60$ after $900 \mathrm{~s}$ of settling time. In this study, lower mean $\mathrm{D}_{\mathrm{f}}$ of particles typically was found for the higher doses of PAC added during the coagulation phase, because fewer small particles remained in the solution due to effective coagulation, which also resulted in better SS removals.
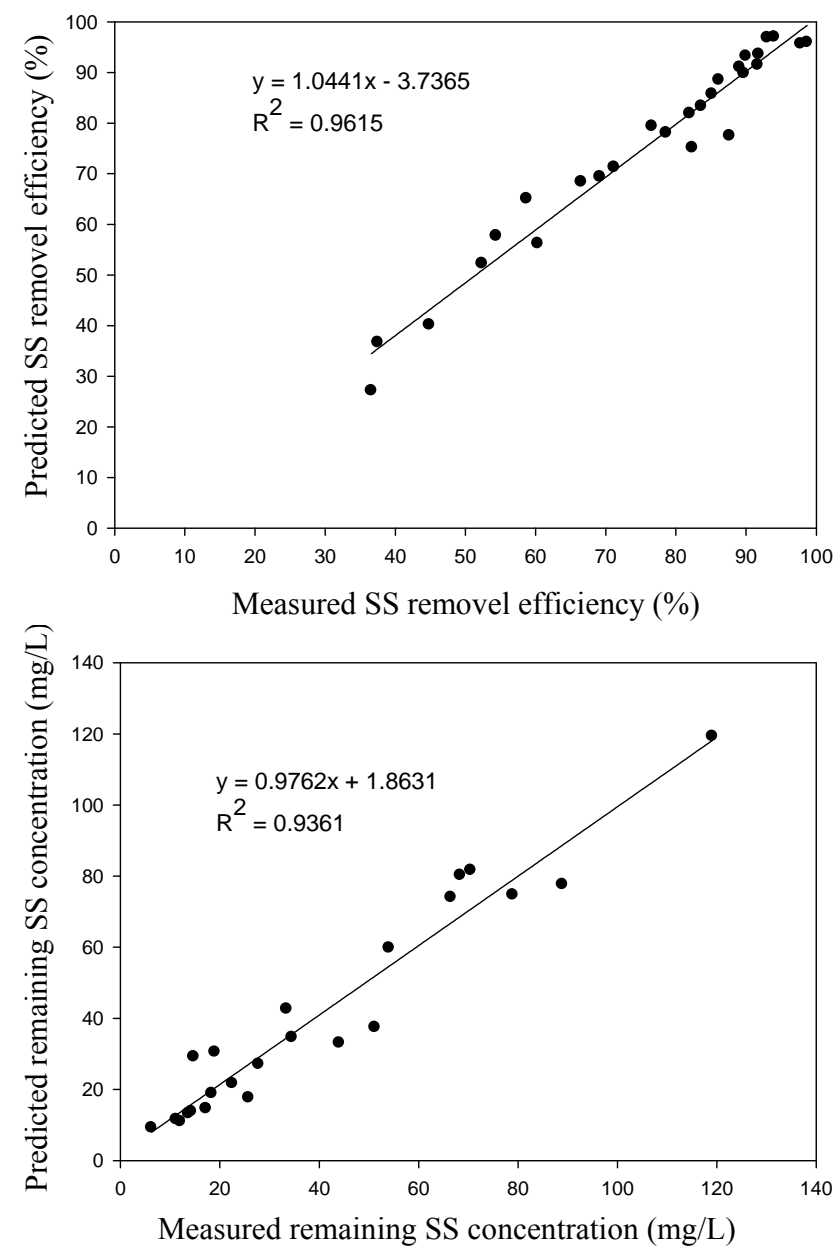

Figure 10. Precise prediction results of BPN models for measured and predicted SS removal efficiencies and remaining SS concentrations.

\subsection{Evaluations of the Removal of SS and Color by the ANN Model and DIA Monitoring}

Typically, the batch settling test is used for the design of the sedimentation tank in wastewater treatment systems. Also, the measurement of suspended solids is based on the total mass of particles in a sample determined by gravimetric analysis, which cannot be conducted on-line. It was noted that the DIA system used in this study can monitor the settling process on-line and simultaneously calculate various parameters of interest during the settling of the particles, including MGV, ED, total area of particles, total volume of particles, and mean fractal dimension of particles $\left(\mathrm{D}_{\mathrm{f}}\right)$. The slopes of the curves of $\mathrm{MGV}$, total area, and total volume of particles also presented some correlations with the SS removal efficiencies. These 
Table 2. Details of the Prediction Results of the BPN and Regression Models in this Study

\begin{tabular}{|c|c|c|c|c|c|c|c|c|c|}
\hline \multirow{2}{*}{ BPN } & \multirow{2}{*}{ Input parameter } & \multirow{2}{*}{ Output } & \multirow{2}{*}{$\mathrm{R}^{2}$} & \multirow{2}{*}{$\begin{array}{l}\text { Network } \\
\text { architecture }\end{array}$} & \multicolumn{3}{|c|}{ Optimization algorithm } & \multicolumn{2}{|c|}{ RMSE } \\
\hline & & & & & Train Cycle & Random Seed & Learn Rate & Train & Test \\
\hline \multirow{4}{*}{$\begin{array}{l}\mathrm{BPN}_{1} \\
\mathrm{BPN}_{2} \\
\mathrm{BPN}_{3} \\
\mathrm{BPN}_{4}\end{array}$} & \multirow{2}{*}{$\begin{array}{l}\text { MGV, S-MGV, ED, } \mathrm{D}_{\mathrm{f}}, \mathrm{TV}, \mathrm{S}-\mathrm{TV} \\
\text { TA, S-TA }\end{array}$} & $\mathrm{SS}_{\mathrm{R}}$ & 0.96 & $8-6-1$ & 25,000 & 0.45 & 1.0 & 0.041 & 0.051 \\
\hline & & $\mathrm{SS}_{\mathrm{E}}$ & 0.94 & $8-5-1$ & 30,000 & 5.0 & 1.0 & 0.089 & 0.091 \\
\hline & \multirow{2}{*}{$\begin{array}{l}\text { MGV, S-MGV, } R_{i}, G_{i}, B_{i}, R_{s}, G_{s}, \\
B_{s}\end{array}$} & Colorr & 0.93 & $8-5-1$ & 25,000 & 0.5 & .04 & 0.110 & 0.102 \\
\hline & & Colore & 0.95 & $8-6-1$ & 20,000 & 1.0 & 0.95 & 0.087 & 0.084 \\
\hline \multicolumn{8}{|c|}{ Regression Equation } & \multicolumn{2}{|c|}{$\mathrm{R}^{2}$} \\
\hline $\mathrm{R}_{1}$ & \multicolumn{9}{|c|}{$\mathrm{SS}_{\mathrm{R}}=85.10+9.51 \times 10^{-2} \mathrm{MGV}+0.87 \mathrm{~S}-\mathrm{MGV}+2.93 \times 10^{-5} \mathrm{ED}-0.11 \mathrm{D}_{\mathrm{f}}-3.95 \times 10^{-4} \mathrm{TV}-4.37 \times 10^{-2} \mathrm{~S}-\mathrm{TV}+3.33 \times 10^{-2} \mathrm{TA}-7.55 \mathrm{~S}-\mathrm{TA}$} \\
\hline $\mathrm{R}_{2}$ & \multicolumn{7}{|c|}{$\mathrm{SS}_{\mathrm{E}}=39.74+0.17 \mathrm{MGV}-1.56 \mathrm{~S}-\mathrm{MGV}-2.86 \times 10^{-5} \mathrm{ED}-5.4 \times 10^{-2} \mathrm{D}_{\mathrm{f}}-8.22 \times 10^{-2} \mathrm{TV}-0.12 \mathrm{~S}-\mathrm{TV}-8.22 \times 10^{-2} \mathrm{TA}+0.12 \mathrm{~S}-\mathrm{TA}$} & \multicolumn{2}{|c|}{0.85} \\
\hline $\mathrm{R}_{3}$ & \multicolumn{7}{|c|}{ Color $_{\mathrm{R}}=1.03 \times 10^{2}-2.60 \times 10^{-4} \mathrm{MGV}+1.99 \times 10^{-2} \mathrm{~S}-\mathrm{MGV}+5.97 \times 10^{3} \mathrm{R}_{\mathrm{i}}+67.60 \mathrm{Gi}_{\mathrm{i}}-6.17 \times 10^{3} \mathrm{~B}_{\mathrm{i}}-0.33 \mathrm{R}_{\mathrm{s}}+0.13 \mathrm{G}_{\mathrm{s}}+0.48 \mathrm{~B}_{\mathrm{s}}$} & \multicolumn{2}{|c|}{0.91} \\
\hline $\mathrm{R}_{4}$ & \multicolumn{7}{|c|}{ Color $_{\mathrm{E}}=7.17 \times 10^{3}-4.03 \mathrm{MGV}+-1.20 \times 10^{4} \mathrm{~S}-\mathrm{MGV}+-1.10 \mathrm{R}_{\mathrm{i}}-4.40 \times 10^{3} \mathrm{G}_{\mathrm{i}}-7.00 \times 10^{3} \mathrm{~B}_{\mathrm{i}}+5.22 \mathrm{R}_{\mathrm{s}}-3.56 \mathrm{G}_{\mathrm{s}}+1.20 \times 10^{-2} \mathrm{~B}_{\mathrm{s}}$} & \multicolumn{2}{|c|}{0.86} \\
\hline
\end{tabular}

*Where $\mathrm{SS}_{\mathrm{R}}\left(\mathrm{SS}\right.$ removal efficiency), $\mathrm{SS}_{\mathrm{E}}\left(\right.$ remaining $\mathrm{SS}$ concentration), Color $\left(\right.$ color removal efficiency), and Color ${ }_{\mathrm{E}}$ (remaining color value).
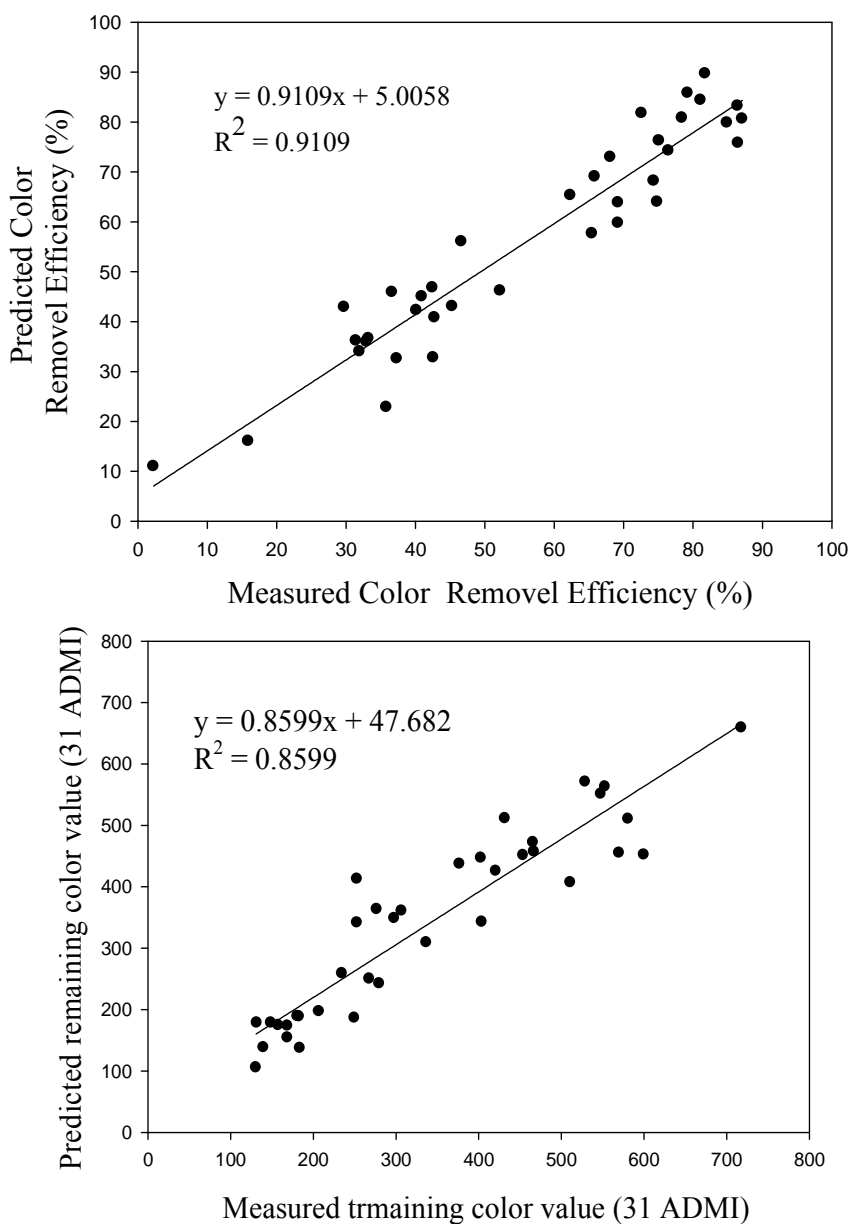

Figure 11. Prediction results of regression models for measured and predicted color removal efficiencies and remaining color values.

on-line monitoring data are helpful for evaluating the SS removal in the batch settling of particles and can provide more effective approaches for the design and control of chemical coagulation. For these purposes, both the regression and ANN models were used to evaluate the removal of SS and color using the DIA monitoring data in this study.

A correlation analysis was conducted to evaluate the correlation coefficients between these parameters and SS remo-
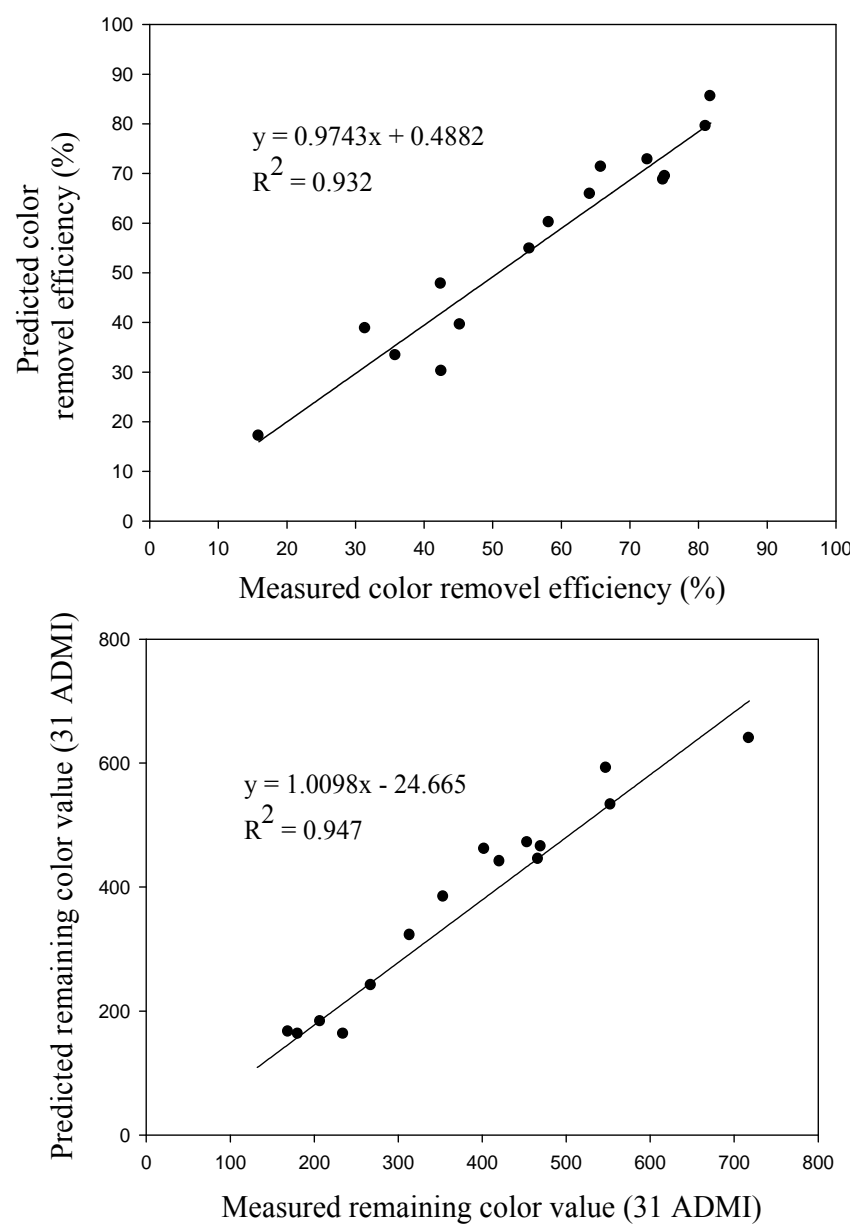

Figure 12. Precise prediction results of BPN models for measureed and predicted color removal efficiencies and remaining color values.

val efficiency and the remaining concentration of SS. The dosage of PAC may be an important parameter for the removal of both SS and color from textile wastewater by chemical coagulation. However, the dosage of PAC was excluded, and only the on-line DIA monitoring parameters were used in the prediction models, because the main aim of this study was to evaluate the feasibility of on-line DIA monitoring for predictting the removal efficiencies for SS and color. In addition, the 
coagulation experiments with textile wastewater at the same dosages of PAC may result in different removal efficiencies for SS and color when the experiments are conducted with different initial SS and color concentrations.

Eight input parameters were used in the regression and BPN models to predict the removal efficiencies for SS and color and to predict the remaining concentrations of SS and color in the effluent. Table 1 shows the detailed identifications of the input parameters for the regression and BPN models. The correlation coefficients $\left(\mathrm{R}^{2}\right)$ of each input parameter with the removal efficiency of SS or color also are presented. Sixty runs of settling experiments were conducted, and datasets consisting of 33 runs and 27 runs were selected randomly for use as training samples and test samples, respectively, in the BPN models.

Table 2 presents the details of the prediction results of the BPN and regression models in this study. For SS removal predictions, Figure 9 shows the prediction results of the regression model in which only acceptable linear correlations with an $\mathrm{R}^{2}$ of 0.88 was obtained for the measured and predicted SS removal efficiencies and an $\mathrm{R}^{2}$ of 0.85 for the measured and predicted remaining SS concentrations, respectively. However, as Figure 10 shows, the BPN models produced very precise predicted results with an $\mathrm{R}^{2}$ of 0.96 for measured and $\mathrm{BPN}$ predicted SS removal efficiencies and an $\mathrm{R}^{2}$ of 0.94 for the measured and predicted effluent SS concentrations. The BPN models presented more precise prediction results for SS removal efficiency and remaining SS concentration than traditional regression models.

The application of chemical coagulation for textile wastewater treatments can remove SS and color, both of which are critically important in the treatment of textile wastewater. The $\mathrm{R} / \mathrm{G} / \mathrm{B}$ color space is defined by the three chromaticities of the red, green, and blue additive primaries, which can produce any chromaticity that is the triangle defined by those primary colors (Hunt, 2004). The DIA system was used to measure the mean $\mathrm{R} / \mathrm{G} / \mathrm{B}$ value of an image that was obtained, which can assist in identifying the true color value of the textile wastewater if proper calibration has been done (Yu et al., 2005). The measurement of $\mathrm{R} / \mathrm{G} / \mathrm{B}$ values also may assist in evaluating color removal from textile wastewater by chemical coagulation. Therefore, another set of BPN models also was developed using the DIA monitoring data to predict simultaneously color removals by the chemical coagulation. The on-line $\mathrm{MGV}$ and $\mathrm{R} / \mathrm{G} / \mathrm{B}$ values were used as input parameters, as presented in Table 1.

The initial and remaining true color values after coagulation also were measured for 37 runs of the previous 60 experimental runs. Therefore, 37 runs of datasets were used for the regression model; datasets of 22 and 15 runs were selected randomly as the training samples and test samples, respectively, in the BPN models. Figure 11 shows the prediction results of the regression model, in which acceptable linear correlations, with $\mathrm{R}^{2}$ values of 0.91 and 0.86 , were obtained for the measured and predicted color removal efficiencies and remaining color values, respectively. However, it also was found that very precise, predicted results were provided by the BPN models, with $\mathrm{R}^{2}$ values of 0.93 and 0.95 for color removal efficiencies and remaining color values, as presented in Figure 12.

As a result, both the removal of SS and color from textile wastewater can be evaluated on-line by the BPN models using DIA monitoring data, thereby providing significant advantages in the control of the use of chemical coagulation for treating textile wastewater.

\section{Conclusions}

An on-line DIA system with a high-resolution CCD was built to monitor the particles in textile wastewater as the particles settled after the addition of a chemical coagulant. DIA monitoring can provide multiple parameters simultaneously, including the $\mathrm{MGV}$ and $\mathrm{R} / \mathrm{G} / \mathrm{B}$ values of the images that are obtained, particle size (ED), total area, total volume, and the fractal dimension of particles. These monitoring parameters were correlated with the removal efficiencies of SS and color, and they were used as the input parameters to the regression and BPN models for evaluating the removal of SS and color by chemical coagulation. The BPN models presented very precise prediction results for the removal efficiencies of SS and color, as well as the remaining SS and color of textile wastewater, with correlation coefficients $\left(\mathrm{R}^{2}\right)$ of 0.96 , $0.94,0.93$, and 0.95 , respectively, which were much higher than those provided by the regression models. As a result, the proposed BPN models, used in conjunction with DIA monitoring, provided significant information that can be used for the simultaneous, on-line evaluation of the removal of SS and color. Also, the models can be used beneficially for the control of the treatment of textile wastewater by chemical coagulation.

Acknowledgments. The authors thank the National Science Council of the Republic of China, Taiwan, for supporting this research financially under Contract No. NSC-95-2622-E-239-006-CC3.

\section{References}

Aguilar, M.I., Saez, J., Llorens, M., Soler, A., and Ortuno, J.F. (2003). Microscopic observation of particle reduction inslaughterhouse wastewater by coagulation-flocculation usingferric sulphate as coagulant and different coagulant aids. Water Res., 37(9), 22332241. http://dx.doi.org/10.1016/S0043-1354(02) 00525-0

APHA, AWWA, WEF. (2005). Standard Methods for the Examination of Water and Wastewater, 21th ed., American Public Health Association, Washington, DC.

Bushell, G. (2005). Forward light scattering to characterise structure of flocs composed of large particles. Chem. Eng. J. 111 (2-3), 145149. http://dx.doi.org/10.1016/j.cej.2005.02.021

Chakraborti, R.K., Atkinson, J.F., and VanBenschoten, J.E. (2000). Characterization of Alum Floc by Image Analysis. Environ. Sci. Technol., 34(18), 3969-3976. http://dx.doi.org/10. 1021/es990818o

Chakraborti, R.K., Gardner, K.H., Atkinson, J.F., and Van Benschoten, J.E. (2003). Changes in fractal dimension during aggregation. Water Res., 37(4), 873-883. http://dx.doi.org/10. 1016/S0043-1354 (02)00379-2 
Cheng, W.P., Kao, Y.P., and Yu, R.F. (2008). A novel method for on-line evaluation of floc size in coagulation process. Water Res., 42(10-11), 2691-2697. http://dx.doi.org/10.1016/S0043-1354(02) 00379-2

Choi, D.J., and Park, H.Y. (2001). A hybrid artificial neural network as a software sensor for optimal control of a wastewater treatment process. Water Res., 35(16), 3959-3967. http:// dx.doi.org/10.1016/ S0043-1354(01)00134-8

Contreras, E.M., Giannuzzia, L., and Zaritzky, N.E. (2004). Use of image analysis in the study of competition between filamentous and non-filamentous bacteria. Water Res., 38(11), 2621-2630. http: //dx.doi.org/10.1016/j.watres.2004.03.022

Ebie, K., Yamaguchi, D., Hoshikawa, H., and Shirozu, T. (2006). New measurement principle and basic performance of high-sensitivity turbidimeter with two optical systems in series. Water Res., 40(4), 683-691. http://dx.doi.org/10.1016/j.watres. 2005.11.032

Elemen, S., Kumbasar, E.P.A., and Yapar, S. (2012). Modeling the adsorption of textile dye on organoclay using an artificial neural network. Dyes Pigment., 95(1), 102-111. http://dx.doi.org/10.1016 /j. dyepig.2012.03.001

Ginoris, Y.P., Amaral, A.L., Nicolau, A., Coelho, M.A.Z., and Ferreira, E.C. (2007). Development of an image analysis procedure for identifying protozoa and metazoa typical of activated sludge system. Water Res., 41(12), 2581-2589. http://dx.doi.org/10.1016 /j.watres.2007.02.006

Govoreanu, R., Saveyn, H., Van der Meeren, P., and Vanrolleghem, P.A. (2004). Simultaneous determination of activated sludge floc size distribution by different techniques. Water Sci. Tech., 50(12), $39-46$.

Gregory, J. (1985).Turbidity fluctuations in flowing suspensions. $J$. Colloid Interface Sci., 105(2), 357-371. http://dx.doi.org/10.1016/ 0021-9797(85)90309-1

Gregory, J. (2009). Monitoring particle aggregation processes. Adv. Colloid Interface Sci., 147-148, 109-123. http://dx.doi.org/10.10 16/j.cis.2008.09.003

Grijspeerdt, K., and Verstraete, W. (1997). Image analysis to estimate the settleability and concentration of activated sludge. Water Res. 31(5), 1126-1134. http://dx.doi.org/10.1016/S00 43-1354(96)0035 $0-8$

He, W., Nan, J., Li, H., and Li, S. (2012). Characteristic analysis on temporal evolution of floc size and structure in low-shear flow. Water Res., 46(2), 509-520. http://dx.doi.org/10.1016/j. watres.20 11.11.040

Huang, C., and Liu, C.B. (1996). Automaticcontrol for chemical-dosing in laboratory-scalecoagulationprocess by using an opti- calmonitor. Water Res., 30(8), 1924-1929. http://dx.doi.org/10.1016/ 0043-1354(96)00068-1

Hunt, R.W.G. (2004) The Reproduction of colour (6th ed.), Chichester UK: Wiley-IS\&T Series in Imaging Science and Technology. ISBN: 0-470-02425-9. http://dx.doi.org/10.1002/0470024275

Jarvis, P., Jeffersona, B., Gregoryb, J., and Parsonsa, S.A. (2005). A review of floc strength and breakage. Water Res., 39(14), 31213137. http://dx.doi.org/10.1016/j.watres.2005.05. 022

Kao, C.M., Chou, M.S., Fang, W.L., Liu, B.W., and Huang, B.R. (2001). Regulating colored textile wastewater by $3 / 31$ wavelength ADMI methods in Taiwan. Chemosphere, 44(5), 1055- 1063. http://dx.doi.org/10.1016/S0045-6535(00)00502-6

Kim, H.S., Kim, Y.J., Cheon, S.P., Baek, G.D., Kim, S.S., and Kim, C.W. (2012). Evaluation of model-based control strategy based on generated setpoint schedules for NH4-N removal in a pilot-scale A2/O process. Chem. Eng. J., 203, 387-397. http://dx.doi.org/10. 1016/j.cej.2012.07.067

Kumar. B.S., and Venkateswarlu, Ch. (2012). Estimating biofilm reaction kinetics using hybrid mechanistic-neural network rate function model. Bioresour. Technol., 103(1), 300-308. http://dx. doi.org/10.1016/j.biortech.2011.10.006

Kumar, P., Prasad, B., Mishra, I.M., and Chand, S. (2008). Treatment of composite wastewater of a cotton textile mill by thermolysis and coagulation. J. Hazard. Mater., 151(2-3), 770-779. http://dx.doi.org/10.1016/j.jhazmat.2007.06.052

Merzouk, B., Gourich, B., Madani, K., Vial, C., and Sekki, A. (2011). Removal of a disperse red dye from synthetic wastewater by chemical coagulation and continuous electrocoagulation, A comparative study. Desalination, 272(1-3), 246-253. http://dx.doi.org/10. 1016/j.desal.2011.01.029

Metcalf \& Eddy. (2002). Wastewater Engineering-treatment, disposal and reuse 4thedn. McGraw-Hill. NY. ISBN: 0-07-1122 50-8, 1217-1330.

Ofir, E., Oren, Y., and Adin, A. (2007). Electroflocculation: the effect of zeta-potential on particle size. Desalination, 204(1-3), 33-38. http://dx.doi.org/10.1016/j.desal.2006.03.533

Papic, S., Koprivanac, N., Bozic, A. L., and Metes, A. (2004). Removal of some reactive dyes from synthetic wastewater bycombined Al(III) coagulation/carbon adsorption process. Dyes Pigment., 62(3), 291-298. http://dx.doi.org/10.1016/S0143-7208(03) 00148-7

Prats-Montalbán, J.M., de Juan, A., and Ferrer, A. (2011). Multivariate image analysis: A review with applications. ChemometricsIntell. Lab. Syst., 107(1), 1-23. http://dx.doi.org/10.1016/j.che molab.2011.03.002

Senthilkumar, M. (2007). Modelling of CIELAB values in vinyl sulphone dye application using feed-forward neural networks. Dyes Pigment., 75(2), 356-361. http://dx.doi.org/10.1016/j.dye pig. 2006.06.010

Schmid, M., Thill, A., Purkhold, U., Walcher, M, Bottero, J. Y., Ginestet, P., Nielsen, P. H., Wuertz, S., Wagner, M. (2003). Characterization of activated sludge flocs by confocal laser scanning microscopy and image analysis. Water Res., 37(9), 2043-2052. http://dx.doi.org/10.1016/S0043-1354(02)00616-4

Sophonsiri, C., and Morgenroth, E. (2004). Chemical composition associated with different particle size fractions in municipal, industrial, and agricultural wastewaters. Chemosphere, 55(5), 691-703. http://dx.doi.org/10.1016/j.chemosphere.2003. 11.032

Verma, A.K., Dash, R.R., and Bhunia, P. (2012). A review on chemical coagulation/flocculation technologies for removal of colour from textile wastewaters. J. Environ. Manage., 93(1), 154-168. http://dx.doi.org/10.1016/j.jenvman.2011.09.012

Verma, S., Prasad, B., and Mishra, I.M. (2010). Pretreatment of petrochemical wastewater by coagulation and flocculation and the sludge characteristics. J. Hazard. Mater., 178(1-3), 1055-1064. http://dx.doi.org/10.1016/j.jhazmat.2010.02.047

Wang, Y., Lu, J., Du, B., Shi, B., Wang, D. (2009). Fractal analysis of polyferric chloride-humic acid (PFC-HA) flocs in different topological spaces. J. Environ. Sci., 21(1), 41-48. http://dx.doi.org/ 10.1016/S1001-0742(09)60009-7

Williams, N.D., Walling, D. E., and Leeks, G.J. (2007). High temporal resolution in situ measurement of the effective particle size characteristics of fluvial suspended sediments. Water Res., 41(5), 1081-1093. http://dx.doi.org/10.1016/j.wa tres.2006.11.010

Wu, C., Wang, Y., Gao, B., Zhao, Y., and Yue, Q. (2012). Coagulation performance and floc characteristics of aluminum sulfate $\mathrm{u}-$ sing sodium alginate as coagulant aid for synthetic dying wastewater treatment. Sep. Purif. Technol., 95, 180-187. http:// dx.doi. org/10.1016/j.seppur.2012.05.009

Yeh, I.C. (2009). Implementation and application of artificial neural network models, 9thedn. Schloars Books Co., Ltd. Taipei. ISBN: 957-499-052-4.

Yu, J., Wang, D., Ge, X., Yan, M., and Yang, M. (2006). Flocculation 
of kaolin particles by two typical polyelectrolytes: A comparative study on the kinetics and floc structures. Colloids Surfaces A: Physicochem. Eng. Aspects., 290(1-3), 288-294. http://dx.doi.org/10. 1016/j.colsurfa.2006.05.040

Yu, R.F., Cheng, W.P., and Chu, M.L. (2005). On-line monitoring of wastewater true color using digital image analysis and ANN. $J$. Environ. Eng., 131(1), 71-79. http://dx.doi.org/10.1061/(AS CE)07 33-9372(2005)131:1(71)

Yu, R.F., Chen, H.W., Cheng, W.P., and Chu, M.L. (2009a). Simultaneously monitoring the particle size distribution, morphology and suspended solids concentration in wastewater applying digital image analysis (DIA). Environ. Monit. Assess., 148(1-4), 19-26. http://dx.doi.org/10.1007/s10661-007-0135-z

Yu, R.F., Chen, H.W., Cheng, W.P., and Hsieh, P.H. (2009b). Dosage control of Fenton process for color removal of textile wastewater applying ORP monitoring and artificial neural network. J. Environ.
Eng., 135(5), 325-332. http://dx.doi.org/10.1061/(ASCE)EE.1943 $-7870.0000016$

Yu, R.F., Lin, C.H., Chen, H.W., Cheng, W.P., and Kao, M.C. (2013). Possible control approaches of the Electro-Fenton process for textile wastewater treatment using on-line moni- toring of DO and ORP. Chem. Eng. J., 218, 341-349. http://dx.doi.org/10.1016/j. cej. 2012.12.061

Zheng, H., Zhu, G., Jiang, S., Tshukudu, T., Xiang, X., and Zhang, P., Q. (2011). He. Investigations of coagulation-flocculation process by performance optimization, model prediction and fractal structure of flocs. Desalination, 269(1-3), 148-156. http://dx.doi.org/ 10.1016/j.desal.2010.10.054

Zhong, R., Zhang, X., Xiao, F., Li, X., and Cai, Z. (2011). Effects of humic acid on physical and hydrodynamic properties of kaolin flocs by particle image velocimetry. Water Res., 45(13), 3981-3990. http://dx.doi.org/10.1016/j.watres.2011.05.006 